\title{
Electronic structure of Lewis acid sites on high surface area aluminium fluorides: a combined XPS and $a b$ initio investigation
}

\author{
Anna Makarowicz, ${ }^{a b}$ Christine L. Bailey, ${ }^{c}$ Norbert Weiher, ${ }^{a b}$ Erhard Kemnitz, ${ }^{d}$ \\ Sven L. M. Schroeder, ${ }^{* a b e}$ Sanghamitra Mukhopadhyay, ${ }^{f}{ }^{\text {Adrian Wander }},{ }^{c}$ \\ Barry G. Searle ${ }^{c}$ and Nicholas M. Harrison ${ }^{c f}$
}

Received 1st December 2008, Accepted 3rd April 2009

First published as an Advance Article on the web 8th May 2009

DOI: $10.1039 / b 821484 k$

High surface area (HS) $\mathrm{AlF}_{3}$ samples have been examined by X-ray photoelectron spectroscopy (XPS). The experimentally observed binding energy (BE) shifts were analysed by reference to core level BEs obtained from ab initio total energy calculations on a range of different, clean and hydroxylated $\alpha$ - and $\beta-\mathrm{AlF}_{3}$ surfaces. Examination of the two components visible in the $\mathrm{Al} 2 \mathrm{p}$ emission indicates that surface $\mathrm{Al}^{3+}$ sites can, depending on the local geometric structure, contribute to both a high BE peak at $77.0 \mathrm{eV}$ and a low BE peak at $76.1 \mathrm{eV}$. Consequently, the areas under the peaks do not quantitatively correlate with surface area or Lewis acidity. However, a significant correlation between the number of surface $\mathrm{Al}$ centres with dangling $\mathrm{F}$ or $\mathrm{OH}$ groups and the appearance of an $\mathrm{Al} 2 \mathrm{p}$ emission component at a $\mathrm{BE}$ lower than in the $\alpha-\mathrm{AlF}_{3}$ bulk is predicted. The experimental $\mathrm{F}$ 1s emission data indicate that dangling $\mathrm{F}$ species are essentially absent. Examination of the $\mathrm{O} 1 \mathrm{~s}$ emission suggests that $\mathrm{HS} \mathrm{AlF}_{3}$ handled at room temperature under any practical laboratory conditions, including glovebox environments, probably contains intrinsically a significant amount of $\mathrm{OH}$ groups and adsorbed water, which results in the covering of $\mathrm{AlF}_{3}$ surfaces by dangling or bridging $\mathrm{OH}$ groups. These Brønsted acid species must be removed by treatment at higher temperature before $\mathrm{HS} \mathrm{AlF}_{3}$ reagents can fully develop their Lewis acidity.

\section{Introduction}

Strong Lewis acid sites at solid surfaces can facilitate the activation of polar bonds in adsorbed molecules, e.g., carbon-halogen cleavage ${ }^{1-3}$ or the cracking and isomerisation of aliphatic hydrocarbons. ${ }^{4}$ To achieve strong Lewis acidity strongly electron-deficient atomic or molecular species must be present at the surface. While the presence of these centres is a prerequisite for the development of any Lewis acidity, their local geometric coordination must also be such that they are accessible to electron-donating reactants. ${ }^{2}$ As a result, the actual strength of the acid sites depends both on the electronic and on the geometric structure at the atomic level.

It has been known for some time that the Lewis acidity of $\mathrm{AlF}_{3}$ species in the gas phase is remarkably high ${ }^{5}$ while crystalline phases of $\mathrm{AlF}_{3}$ exhibit moderate to no acidity in

\footnotetext{
${ }^{a}$ Molecular Materials Centre, The University of Manchester,

Sackville Street, PO Box 88, Manchester, UK M60 1QD.

E-mail:s.schroeder@manchester.ac.uk

${ }^{b}$ School of Chemical Engineering and Analytical Science,

The University of Manchester, Sackville Street, PO Box 88 ,

Manchester, UK M60 1QD

${ }^{c}$ STFC Daresbury Laboratory, Daresbury, Warrington, Cheshire,

UK WA4 $4 A D$

${ }^{d}$ Institute of Chemistry, Humboldt University of Berlin, Brook Taylor

Straße 2, 12489 Berlin, Germany

${ }^{e}$ School of Chemistry, The University of Manchester,

Brunswick Street, Manchester, UK M13 9PL

${ }^{f}$ Department of Chemistry, Imperial College London, London,

$U K S W 72 A Z$
}

chemical reactions. ${ }^{2}$ Crystalline $\mathrm{AlF}_{3}$ can exist in various polymorphic forms that consist of corner-sharing $\left[\mathrm{AlF}_{6}\right]$-octahedra ${ }^{6}$ arranged in regular networks. The bonding in $\mathrm{AlF}_{3}$ is strongly ionic and as a consequence the bulk polymorphs all have very similar electronic structure. ${ }^{7}$ This suggests that it is the geometric structure of the surfaces that is responsible for the occurrence of Lewis acidity; $\alpha-\mathrm{AlF}_{3}$ exhibits almost no Lewis acidity while $\beta-\mathrm{AlF}_{3}$ exhibits moderate Lewis acidity. This variation of Lewis acidity has been the subject of recent theoretical investigations. ${ }^{8-11}$

The high lattice energy of $\mathrm{AlF}_{3}$ favours the formation of crystalline phases. Traditional preparation routes use high temperatures to facilitate ordering and/or sintering. ${ }^{2}$ Recently, sol-gel synthesis methods have been developed that proceed under sufficiently mild conditions to prevent the formation of ordered crystalline $\left[\mathrm{AlF}_{6}\right]$-networks. ${ }^{12,13}$ The synthesis of these materials starts with the fluorination of an aluminium alkoxide with an anhydrous alcoholic HF solution, which leads to the formation of an aluminium alkoxide fluoride precursor material. This solid precursor material, which is still strongly solvated, ${ }^{12}$ is subsequently fluorinated with a chlorofluorocarbon $(\mathrm{CFC})$ such as CFC-12 $\left(\mathrm{CCl}_{2} \mathrm{~F}_{2}\right)$ or CFC-22 $\left(\mathrm{CHClF}_{2}\right)$ under mild conditions, i.e., with a dilute $\mathrm{CFC}$ stream in a flow reactor at temperatures between $523 \mathrm{~K}$ and $573 \mathrm{~K}$. This treatment leads to high surface area (HS) $\mathrm{AlF}_{3}{ }^{12,13}$ with BET surface areas of a few $100 \mathrm{~m}^{2} \mathrm{~g}^{-1}$.

In contrast to crystalline $\mathrm{AlF}_{3}$ polymorphs, the non-crystalline $\mathrm{HS} \mathrm{AlF}_{3}$ materials achieve Lewis acidities similar to those of 
gas phase $\mathrm{AlF}_{3} \cdot{ }^{12-14}$ However, the nature of the strong Lewis acid sites in these materials is not fully understood at the molecular level. A number of probes, including XPS, ${ }^{15-18}$ FTIR, ${ }^{14,19}$ NMR, ${ }^{12,20,21}$ and ESR, ${ }^{22,23}$ have previously been applied to provide information on the electronic state of surface atoms in aluminium fluorides and oxyfluorides. Most relevant in the context of $\mathrm{HS} \mathrm{AlF}_{3}$ is a recent ${ }^{14}$ FTIR study of $\mathrm{CO}$ adsorption. The strong blue shifts of the $\mathrm{CO}$ stretching vibration and the intensity of the band indicated that $\mathrm{HS} \mathrm{AlF}_{3}$ contains a large number of very strong Lewis acid sites. ${ }^{14}$ The spectrum for $\beta-\mathrm{AlF}_{3}$ showed that the majority of sites on this material are much weaker Lewis sites, with only a small proportion of sites as strong as those on $\mathrm{HS} \mathrm{AlF}_{3}$. Theoretical investigations of the under-coordinated $\mathrm{Al}$ ions exposed at the stoichiometric (100), (010) and (001) surfaces of $\beta-\mathrm{AlF}_{3}$ show that the strongest $\mathrm{Al}$ sites occur on the type 1 (T1) termination of the (100) surface, ${ }^{24,25}$ but only approximately $4 \%$ of the surface area of a $\beta-\mathrm{AlF}_{3}$ crystallite at equilibrium morphology is predicted to expose the (100) surface. ${ }^{9}$ It can therefore be hypothesised that the strong Lewis acid sites found in small quantities on $\beta-\mathrm{AlF}_{3}$ will be present in much larger quantities on $\mathrm{HS} \mathrm{AlF}_{3}$.

In the present paper we examine how core level binding energy (BE) data of $\mathrm{HS} \mathrm{AlF}_{3}$ materials relate to the local coordination environment of the $\mathrm{Al}$ centres. We compare XPS data to core level BE shifts obtained from $a b$ initio calculations, and propose how to interpret the variations in the XP spectra for a number of $\mathrm{HS} \mathrm{AlF}_{3}$ materials with varying surface areas in terms of local geometric structure. We show that a rather detailed understanding of the relationship between the core level BEs and the chemical and structural properties of the associated surface species is required in order to interpret the core level BE shifts correctly and meaningfully.

\section{Experimental}

The synthesis of the $\mathrm{HS} \mathrm{AlF}_{3}$ materials was performed at the HU Berlin as described previously. ${ }^{12,13}$ Briefly, an aluminium isopropoxide, $\mathrm{Al}(\mathrm{i}-\mathrm{OPr})_{3}$, suspension in isopropanol was treated with anhydrous $\mathrm{HF}$ (dissolved in diethyl ether, $\mathrm{Et}_{2} \mathrm{O}$ ) to form an $\mathrm{AlF}_{3-x}(\mathrm{i}-\mathrm{OPr})_{x}$ precursor. Further treatment with $\mathrm{CHClF}_{2}(\mathrm{CFC}-22)$ or $\mathrm{CCl}_{2} \mathrm{~F}_{2}(\mathrm{CFC}-12)$ in a solid-gas reaction led to the desired $\mathrm{HS} \mathrm{AlF}_{3}$ materials.

After fluorination, the $\mathrm{HS} \mathrm{AlF}_{3}$ materials were kept under an $\operatorname{Ar}(99.9 \%)$ protecting atmosphere in the reactor, which was closed and transferred into a glovebox before re-opening. In the glovebox, several aliquots of each $\mathrm{HS} \mathrm{AlF}_{3}$ material were filled into separate glass ampoules, which were sealed by melting the glass. Samples were transferred from Berlin to Manchester inside these ampoules. They were opened only immediately prior to XRD (Philips D8 powder diffractometer, Bragg-Brentano geometry, rotating sample stage) and XPS (see below for technical details) investigations. Before XPS measurements, exposure of the samples to the laboratory ambient was at maximum a few minutes. Unused sample material from the opened ampoules was transferred into standard laboratory sample vials sealed by polyethylene or nylon push-on caps, and kept in these containers for later investigations.

None of the $\mathrm{HS} \mathrm{AlF}_{3}$ materials had a discernible XRD pattern, indicating the absence of any material with long-range order. In line with this, BET surface areas varied from $113 \mathrm{~m}^{2} \mathrm{~g}^{-1}$ to $188 \mathrm{~m}^{2} \mathrm{~g}^{-1}$. These are common values found for the fluorination temperatures and durations applied during the synthesis. Lower temperatures and longer fluorination times can result in materials with even higher BET surface areas (one such sample will be described below). As can be seen from the following experimental details, there are no obvious correlations between the slight changes in fluorination conditions and the surface area or the residual carbon content of the samples:

(i) $\mathrm{HS} \mathrm{AlF}_{3}$ with a BET surface area of $113 \mathrm{~m}^{2} \mathrm{~g}^{-1}$ (in the following referred to as ' $\mathrm{HS} 113 \mathrm{~m}^{2} \mathrm{~g}^{-1}$ '), which was obtained by heating the precursor in a flow of $\mathrm{CHF}_{2} \mathrm{Cl}\left(5 \mathrm{ml} \mathrm{min}^{-1}\right)$ and $\mathrm{N}_{2}\left(20 \mathrm{ml} \mathrm{min}^{-1}\right)$ to $553 \mathrm{~K}$ and held at this temperature until $\mathrm{CHF}_{2} \mathrm{Cl}$ conversion was $98.2 \%$. Total time of fluorination was $15 \mathrm{~h} 50 \mathrm{~min}$. The elemental analysis of the resulting sample indicated a residual carbon content of $0.5 \%$.

(ii) $\mathrm{HS} \mathrm{AlF}_{3}$ with a BET surface area of $116 \mathrm{~m}^{2} \mathrm{~g}^{-1}$ (in the following referred to as 'HS $116 \mathrm{~m}^{2} \mathrm{~g}^{-1}$ '), which was obtained by heating the precursor in a flow of $\mathrm{CHF}_{2} \mathrm{Cl}\left(5 \mathrm{ml} \mathrm{min}^{-1}\right)$ and $\mathrm{N}_{2}\left(20 \mathrm{ml} \mathrm{min}^{-1}\right)$ to $583 \mathrm{~K}$ and held at this temperature until $\mathrm{CHF}_{2} \mathrm{Cl}$ conversion was $97.3 \%$. Total time of fluorination was $18 \mathrm{~h} 20 \mathrm{~min}$. The elemental analysis of the resulting sample indicated a residual carbon content of $0.7 \%$.

(iii) $\mathrm{HS} \mathrm{AlF}_{3}$ with a BET surface area of $144 \mathrm{~m}^{2} \mathrm{~g}^{-1}$ (in the following referred to as ' $\mathrm{HS} 144 \mathrm{~m}^{2} \mathrm{~g}^{-1}$ '), which was obtained by heating the precursor in a flow of $\mathrm{CF}_{2} \mathrm{Cl}_{2}\left(5 \mathrm{ml} \mathrm{min}{ }^{-1}\right)$ and $\mathrm{N}_{2}\left(20 \mathrm{ml} \mathrm{min}^{-1}\right)$ to $573 \mathrm{~K}$ and held at this temperature until $\mathrm{CF}_{2} \mathrm{Cl}_{2}$ conversion was $98.1 \%$. Total time of fluorination was $15 \mathrm{~h}$. The elemental analysis of the resulting sample indicated a residual carbon content of $0.1 \%$.

(iv) $\mathrm{HS} \mathrm{AlF}_{3}$ with a BET surface area of $160 \mathrm{~m}^{2} \mathrm{~g}^{-1}$ (in the following referred to as ' $\mathrm{HS} 160 \mathrm{~m}^{2} \mathrm{~g}^{-1}$ '), which was obtained by heating the precursor in a flow of $\mathrm{CHF}_{2} \mathrm{Cl}\left(5 \mathrm{ml} \mathrm{min}^{-1}\right)$ and $\mathrm{N}_{2}\left(20 \mathrm{ml} \mathrm{min}^{-1}\right)$ to $573 \mathrm{~K}$ and held at this temperature until $\mathrm{CHF}_{2} \mathrm{Cl}$ conversion was $93.2 \%$. Total time of fluorination was $14 \mathrm{~h} 40 \mathrm{~min}$. The elemental analysis of the resulting sample indicated a residual carbon content of $0.6 \%$.

(v) $\mathrm{HS} \mathrm{AlF}_{3}$ with a BET surface area of $188 \mathrm{~m}^{2} \mathrm{~g}^{-1}$ (in the following referred to as 'HS $188 \mathrm{~m}^{2} \mathrm{~g}^{-1}$ '), which was obtained by heating the precursor in a flow of $\mathrm{CHF}_{2} \mathrm{Cl}\left(5 \mathrm{ml} \mathrm{min}^{-1}\right)$ and $\mathrm{N}_{2}\left(20 \mathrm{ml} \mathrm{min}^{-1}\right)$ to $533 \mathrm{~K}$ and held at this temperature until $\mathrm{CHF}_{2} \mathrm{Cl}$ conversion was $98.4 \%$. Total time of fluorination was $10 \mathrm{~h} 50 \mathrm{~min}$. The elemental analysis of the resulting sample indicated a residual carbon content of $0.6 \%$.

(vi) Crystalline $\alpha-\mathrm{AlF}_{3}$ obtained by sublimation was supplied by Pharmpur GmbH (Königsbrunn, Germany). A crystallite of several $\mathrm{mm}$ diameter in all three dimensions was freshly cleaved along the $(01 \overline{1} 2)$ plane immediately before mounting on the sample holder and insertion into the load lock of the XPS system. The cleaved surface was exposed to the laboratory ambient for not more than $60 \mathrm{~s}$.

We will also report XRD data (Fig. 5) for a sample of HS $\mathrm{AlF}_{3}$ with a BET surface area of $309 \mathrm{~m}^{2} \mathrm{~g}^{-1}$ ('HS $309 \mathrm{~m}^{2} \mathrm{~g}^{-1}$ ), which was stored in a standard vial in the laboratory for 
5 months. This sample had been obtained by a comparatively mild fluorination process with $\mathrm{CHClF}_{2}$ at lower temperatures. The fluorination temperature was first raised to $423 \mathrm{~K}(2 \mathrm{~h})$, then to $473 \mathrm{~K}(2 \mathrm{~h})$ and finally to $543 \mathrm{~K}$ where it was held until the $\mathrm{CHClF}_{2}$ conversion was $98 \%$.

XPS data were acquired with a KRATOS Axis Ultra system, using a monochromatised $\mathrm{Al} \mathrm{K}_{\alpha} \mathrm{X}$-ray source (operating at a power of $150 \mathrm{~W}$ ) and a spherical mirror electron analyser. High-resolution scans of the relevant core level emission lines were taken with an energy grid of $0.1 \mathrm{eV}$ and a pass energy of $20 \mathrm{eV}$. Data acquisition times for each core level were approximately $10 \mathrm{~min}$. During data acquisition the Kratos charge neutraliser was switched on at all times. The analysis of the data was carried out using CASAXPS. ${ }^{26}$ The F 1s photoemission peaks were fitted with two GaussianLorentzian (GL) peaks, with a full width at half-maximum (FWHM) constrained to $2.8 \mathrm{eV}$, except in the cases of HS $113 \mathrm{~m}^{2} \mathrm{~g}^{-1}$ and HS $144 \mathrm{~m}^{2} \mathrm{~g}^{-1}$, where one GL peak with a FWHM of $2.8 \mathrm{eV}$ was sufficient, and of $\alpha-\mathrm{AlF}_{3}$, where one GL peak with a FWHM of $1.8 \mathrm{eV}$ was sufficient. The Al 2 p photoemission peaks were fitted with two GL peaks, except in the cases of HS $160 \mathrm{~m}^{2} \mathrm{~g}^{-1}$, HS $188 \mathrm{~m}^{2} \mathrm{~g}^{-1}$ and $\alpha-\mathrm{AlF}_{3}$, where, respectively, single peaks with FWHMs of $2.2 \mathrm{eV}, 2.2 \mathrm{eV}$ and $1.8 \mathrm{eV}$ were sufficient to model the experimental data. Two GL peaks were always fitted for the $\mathrm{O} 1 \mathrm{~s}$ photoemission peaks, each component with a FWHM fixed at $2.7 \mathrm{eV}$. The Shirley method $^{27}$ was used in all cases to model the spectral background. The $\mathrm{C} 1 \mathrm{~s}$ emission from adventitious surface hydrocarbon contamination at $284.8 \mathrm{eV}$ was identified by a careful curve-fitting procedure for the $\mathrm{C} 1$ s region of the spectrum ${ }^{28}$ and used as the binding energy reference. ${ }^{29}$ The source of adventitious hydrocarbon contamination is unlikely to be carbonaceous contamination in the original samples but is likely to be due to adsorption from the residual gas in the ultra-high vacuum chamber of the XPS system, where aliphatic hydrocarbons are produced by electron-induced cracking of vacuum contaminants at glowing filaments inside the chamber. Radiation-induced decomposition of more complex organic contaminants ${ }^{28}$ acquired, e.g., during handling the samples in the laboratory, might contribute to the observed hydrocarbon surface concentration as well.

It should be noted that the core level BEs determined in this study are significantly lower than previously reported values (e.g., $76.5 \mathrm{eV}$ for the $\mathrm{Al} 2 \mathrm{p}$ emission from $\alpha-\mathrm{AlF}_{3}$ compared to $77.3 \mathrm{eV}^{17}$ and $77.1 \mathrm{eV}^{18}$ ). However, all values reported here were reproducible with our instrument to within $\pm 0.1 \mathrm{eV}$. We can exclude the possibility of a BE scale calibration error because we verified regularly with $\mathrm{Cu}, \mathrm{Ag}$ and $\mathrm{Au}$ foil standards that the energy scale of the XPS electron analyser was accurately calibrated to within $\pm 0.1 \mathrm{eV} .{ }^{30,31}$ In fact, over a period of 2 years, all $\mathrm{BE}$ values determined for $\mathrm{AlF}_{3}$ materials with our instrument were reproducible to within this margin. We conclude that the systematically lower BE values reported here are related to the use of a charge neutralisation system in the present study, which minimised surface charging. This conclusion is supported by the fact that the observed FWHM of the $\mathrm{Al} 2 \mathrm{p}$ emission from $\alpha-\mathrm{AlF}_{3}(1.8 \mathrm{eV}$, Table 1$)$ is close to the best resolution that can be obtained with our instrument, and significantly lower than values reported in previous studies $\left(2.1 \mathrm{eV}^{17}\right.$ and $\left.3.0 \mathrm{eV}^{18}\right)$. The $\mathrm{BE}$ of $\mathrm{F} 1 \mathrm{~s}$ in $\alpha-\mathrm{AlF}_{3}$ was found to be $686.7 \mathrm{eV}$ (Fig. 3, top spectrum), which similarly deviates from previously reported values $\left(687.75 \mathrm{eV}^{17}\right.$ and $\left.687.5 \mathrm{eV}^{18}\right)$ by being significantly lower. The FWHM of the F 1s peak is $1.8 \mathrm{eV}$, which is again close to the instrumental resolution limit and significantly lower than the previously reported values (1.97 $\mathrm{eV}^{17}$ and $2.8 \mathrm{eV}^{18}$ ), supporting the conclusion that reduced charging is the origin of the observed $\mathrm{BE}$ deviations.

Calculations were performed using the CRYSTAL code, ${ }^{32,33}$ wherein the hybrid exchange B3LYP functional was employed. ${ }^{34,35}$ This functional has been shown to model the energetic, geometric and electronic properties of materials with significantly greater accuracy ${ }^{36}$ than gradient corrected functionals and it has previously been shown to provide an excellent description of $\alpha-\mathrm{AlF}_{3}{ }^{8,10}$ and $\beta-\mathrm{AlF}_{3}{ }^{{ }^{9-11}}$ The radial functions of the atomic orbitals were expressed as a linear combination of Gaussian type functions. High quality triple valence basis sets with polarisation functions at the all electron level were used throughout and are defined in full in previous papers. ${ }^{9,37}$

In CRYSTAL, the convergence of the real space summation of the Coulomb and exchange contributions to the Hamiltonian matrix are controlled by five overlap criteria. The control of these approximations is described in detail elsewhere. $^{32}$ The values used in this study were $10^{-8}, 10^{-8}$, $10^{-8}, 10^{-8}$, and $10^{-16}$, which results in a numerical error in the total energies of order $1 \times 10^{-6}$ Hartree per $\mathrm{AlF}_{3}$ formula unit. A Monkhorst-Pack shrinking factor of eight was used to sample the first Brillouin zone, and a denser Gilat net consisting of 16 points was used in the evaluation of the Fermi energy and density matrix. ${ }^{32}$ This results in a numerical error in the total energies of less than $1 \times 10^{-10}$ Hartree per $\mathrm{AlF}_{3}$ formula unit. The surfaces were modelled using slabs of material periodic in two dimensions with either a mirror or glide symmetry operator acting perpendicular to the surface as to maintain top/bottom symmetry within the slabs. As all the slabs have a mirror plane perpendicular to the surface and all the surfaces are non-polar no macroscopic dipoles arise. The surface energies of the slabs used in this study were converged to better than $0.01 \mathrm{~J} \mathrm{~m}^{-2}$ with respect to slab thickness. Resultant slabs were all at least $14 \AA$ thick. The core level BEs of the atoms at the centre of these slabs were converged

Table 1 Core level BEs and associated FWHMs of the peaks obtained through the fitting analysis of the experimental XPS data

\begin{tabular}{llll}
\hline & $\begin{array}{l}\text { Al 2p } \\
\text { BE (FWHM) } \\
\text { eV }\end{array}$ & $\begin{array}{l}\text { F 1s } \\
\text { BE (FWHM) } \\
\text { eV }\end{array}$ & $\begin{array}{l}\text { O 1s } \\
\text { BE (FWHM)/ } \\
\text { eV }\end{array}$ \\
\hline HS $113 \mathrm{~m}^{2} \mathrm{~g}^{-1}$ & $76.2(2.2)$ & $686.5(2.8)$ & $532.5(2.7)$ \\
& $77.1(2.2)$ & & $534.0(2.7)$ \\
HS $116 \mathrm{~m}^{2} \mathrm{~g}^{-1}$ & $76.1(2.2)$ & $686.6(2.8)$ & $532.4(2.7)$ \\
& $77.1(2.2)$ & $686.9(2.1)$ & $533.8(2.7)$ \\
HS $144 \mathrm{~m}^{2} \mathrm{~g}^{-1}$ & $76.0(2.2)$ & $686.7(2.8)$ & $532.5(2.7)$ \\
HS $160 \mathrm{~m}^{2} \mathrm{~g}^{-1}$ & $76.9(2.2)$ & & $534.1(2.7)$ \\
& $76.3(2.2)$ & $686.6(2.8)$ & $532.9(2.7)$ \\
HS $188 \mathrm{~m}^{2} \mathrm{~g}^{-1}$ & $76.1(2.2)$ & $687.1(2.8)$ & $535.0(2.7)$ \\
$\alpha-\mathrm{AlF}_{3}$ & $76.6(1.8)$ & $686.3(2.8)$ & $532.5(2.7)$ \\
& & $686.8(2.8)$ & $534.2(2.7)$ \\
& & & $532.4(2.7)$ \\
\hline
\end{tabular}


with respect to bulk core level binding energies. Optimisation of the surface structures was performed by energy minimisation using a damped molecular dynamics optimiser and structures were assumed to be converged when the resultant forces in all symmetry allowed directions were below $1 \times 10^{-4}$ Hartree per Bohr.

The calculations were performed for a variety of low energy surface structures that were identified in previous studies. ${ }^{8,9}$ The $\alpha-\mathrm{AlF}_{3}(01 \overline{1} 2)(\sqrt{ } 2 \times \sqrt{ } 2)$ surface was considered as it has been shown to dominate on $\alpha$-crystallites ${ }^{9,38}$ and its Lewis acid sites are also very similar to those on the predicted dominant surface on $\beta-\mathrm{AlF}_{3}$ crystallites. ${ }^{9}$ This surface, shown in Fig. 1a, consists of surface $\mathrm{Al}$ ions that are bound to four bridging $\mathrm{F}$ ions and a dangling $\mathrm{F}$ ion. The $\alpha-\mathrm{AlF}_{3}(0001)$ surface, which consists of four-fold coordinated $\mathrm{Al}$ ions bound to one dangling $\mathrm{F}$ ion and five-fold $\mathrm{Al}$ ions bound to two dangling F ions, was also considered. This surface, shown in Fig. 1b, provides a reference for four-fold $\mathrm{Al}$ ions. At equilibrium morphology, approximately $4 \%$ of the surface area of crystalline $\alpha-\mathrm{AlF}_{3}$ consists of this surface. Furthermore, the (001) surface exposed on $\beta-\mathrm{AlF}_{3}$ contains similar four-fold $\mathrm{Al}$ sites.

The $\mathrm{T} 1$ termination of $\beta-\mathrm{AlF}_{3}$ (100) was also studied, because, as discussed above, it is thought to contain sites representative of strong Lewis acid sites present on HS $\mathrm{AlF}_{3}{ }^{9,24,25}$ This surface, shown in Fig. 1c, consists of two repeating rows of $\mathrm{Al}$ ions (labelled row $\mathrm{A}$ and row $\mathrm{B}$ ) that are bound to five bridging $\mathrm{F}$ ions, alternate $\mathrm{Al}$ ions are six-fold coordinated as they are also bound to a dangling $\mathrm{F}$ ion.

As the surfaces are exposed to water vapour, both during synthesis and when subsequently exposed to air, surface hydroxylation is likely to occur (see also discussion further below). It has been shown that hydroxylation of bridging
F ions is thermodynamically more favourable than hydroxylation of dangling $\mathrm{F}$ ions, ${ }^{37}$ but it should be kept in mind that kinetic parameters could hinder any hydroxylation taking place. Recently calculated phase diagrams for the composition of $\alpha-\mathrm{AlF}_{3}$ surfaces in the presence of $\mathrm{H}_{2} \mathrm{O}$ and $\mathrm{HF}$ indicate that, at room temperature and in the absence of any measurable $\mathrm{HF}$ pressure, the hydroxylated and/or hydrated states of the surfaces are thermodynamically more stable than oxygen-free fluoride terminations - even at environmental $\mathrm{H}_{2} \mathrm{O}$ partial pressures of $10^{-7}$ mbar. As will be argued in the section on $\mathrm{O}$ 1s emission from $\mathrm{HS} \mathrm{AlF}_{3}$ below, even $\mathrm{H}_{2} \mathrm{O}$ pressures of $10^{-6}$ mbar (impractical in gloveboxes) would be sufficient to readily cover the whole sample surface with adsorbed $\mathrm{H}_{2} \mathrm{O}$. This suggests that $\mathrm{HS} \mathrm{AlF}_{3}$, which is much more reactive than $\alpha-\mathrm{AlF}_{3}$, will at room temperature under any practical conditions almost instantly be modified by adsorbed water and very likely also by hydroxylation. We will show below that we did not find any evidence for the presence of dangling F-species, suggesting that their hydrolysis by adsorption of $\mathrm{H}_{2} \mathrm{O}$ is rapid or, probably less likely, that these species are not formed at all during the $\mathrm{HS} \mathrm{AlF}_{3}$ synthesis. Calculated phase diagrams ${ }^{37}$ for $\alpha-\mathrm{AlF}_{3}$ suggest that non-hydroxylated surfaces free of adsorbed water can in practice be prepared at temperatures around $600 \mathrm{~K}$, but reducing the temperature will, under any conditions achievable in laboratory practice, invariably lead to the formation of hydroxylated surfaces and to water adsorption. In line with this, previous IR analysis of $\mathrm{HS} \mathrm{AlF}_{3}$ handled at room temperature indicated that it always contained a significant concentration of $\mathrm{OH}$ groups and/or strongly adsorbed water. ${ }^{14}$

For the computational evaluation of the XPS core level shifts we therefore considered a range of surfaces in
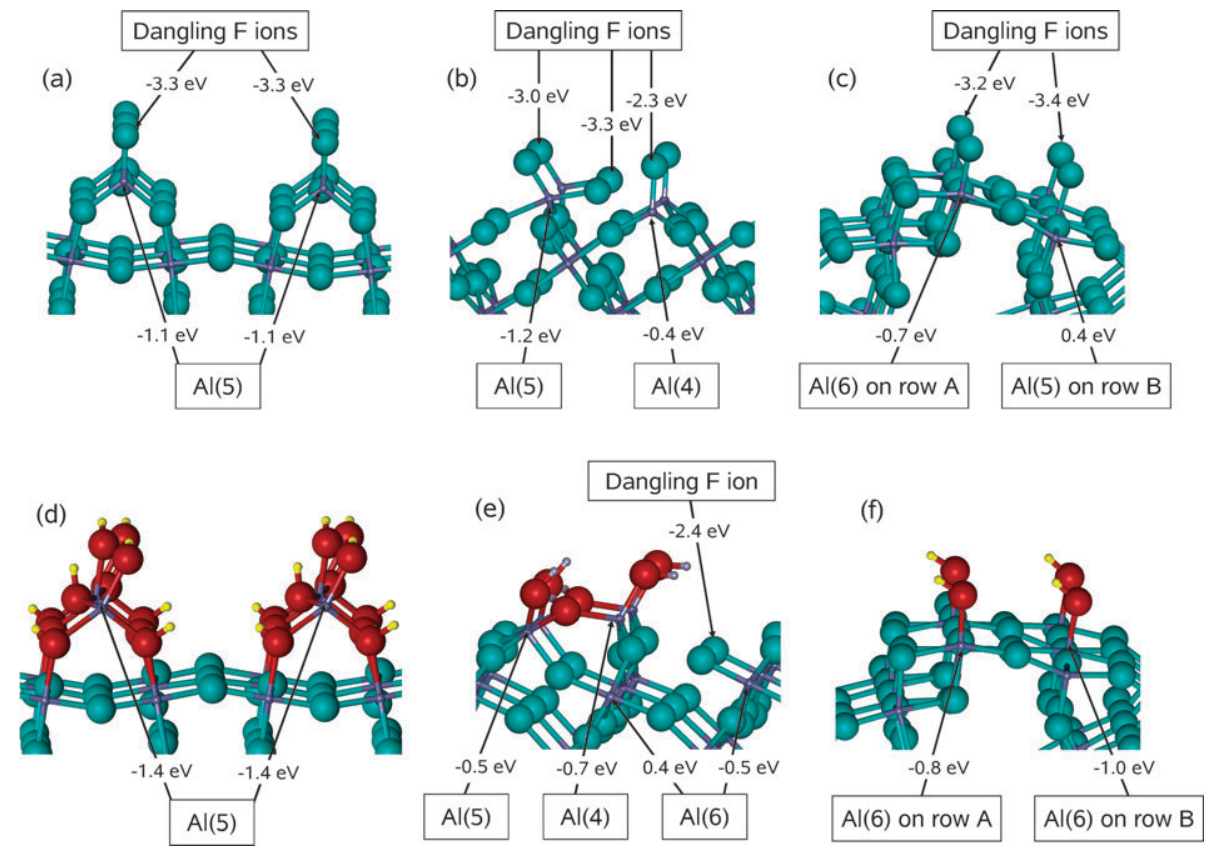

Fig. 1 The F 1s and Al 2p BE shifts, relative to bulk species, for various surface atoms. (a) The $\alpha-\mathrm{AlF}_{3}(01 \overline{1} 2)$ surface. (b) The $\beta-A l F_{3}(100) \mathrm{T} 1$ surface. (c) The $\alpha-\mathrm{AlF}_{3}$ (0001) surface. (d) The hydroxylated $\alpha-\mathrm{AlF}_{3}(01 \overline{1} 2)$ surface. (e) The hydroxylated $\beta-\mathrm{AlF}_{3}$ (100) T1 surface. (f) The hydroxylated $\alpha-\mathrm{AlF}_{3}(0001)$ surface. 
which both dangling and bridging $\mathrm{F}$ ions were replaced by $\mathrm{OH}$ groups. The adsorption of water onto the hydroxylated $\beta-\mathrm{AlF}_{3}$ (100) surface was considered as well. The structures investigated here are therefore typical of those likely to occur on real samples under realistic ranges of temperature and pressure. ${ }^{9,14}$ The structures of these hydroxylated surfaces are shown in Fig. 1d-f.

The Al 2p and F 1s core level shifts have been computed as eigenvalue differences between surface atoms and atoms in the centre of the slab. This approximation neglects the effects of final state relaxation, which are assumed to be systematic and therefore to have a minor effect on the estimated shifts. The absolute $\mathrm{O} 1 \mathrm{~s}$ BEs have also been calculated for each system. However, it is not possible to compare these values to the experimental energies as there is no oxygen in the bulk material to act as a reference energy.

\section{Results and discussion}

\section{Al 2p}

The results of the peak fitting analysis of the Al $2 \mathrm{p}$ emission data (Fig. 2) are summarised in Table 1. The single peak of the stoichiometric $\alpha-\mathrm{AlF}_{3}$ reference phase has its centre at a $\mathrm{BE}$ of approximately $76.6 \mathrm{eV}$ (top spectrum in Fig. 2). As the Al 2p $\mathrm{BE}$ is low, the kinetic energy of the emitted electrons is, at approximately $1400 \mathrm{eV}$, quite high and their emission is not particularly surface sensitive, with exponential attenuation constants of approximately $50 \AA{ }^{39}$ The $\mathrm{Al} 2 \mathrm{p}$ emission can thus be considered to be a bulk probe of $\alpha-\mathrm{AlF}_{3}$.

The $\mathrm{Al} 2 \mathrm{p}$ emission of all the $\mathrm{HS} \mathrm{AlF}_{3}$ samples exhibits a main component centred at a lower $\mathrm{BE}$, at approximately $76.1 \mathrm{eV}$, shifted by $0.5 \mathrm{eV}$ relative to bulk $\alpha-\mathrm{AlF}_{3}$. Additionally, for most of the $\mathrm{HS} \mathrm{AlF}_{3}$ samples (the exceptions being $\mathrm{HS}$ $160 \mathrm{~m}^{2} \mathrm{~g}^{-1}$ and HS $188 \mathrm{~m}^{2} \mathrm{~g}^{-1}$ ), a weaker component is visible at higher BEs, at around $77.0 \mathrm{eV}$. Assuming spherical particle

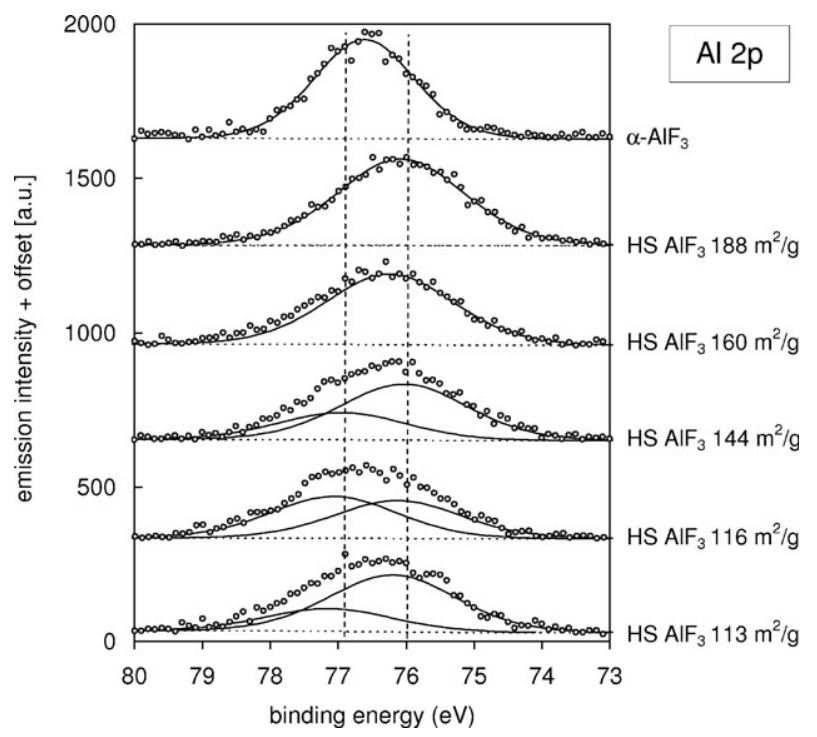

Fig. $2 \mathrm{Al} 2 \mathrm{p}$ photoemission data for $\alpha-\mathrm{AlF}_{3}$ and several $\mathrm{HS} \mathrm{AlF}_{3}$ samples. The intensity of the spectra was scaled to result in approximately equal peak heights. shapes, the surface areas of $\mathrm{HS} \mathrm{AlF}_{3}$ suggest average particle radii on the order of $10 \mathrm{~nm}$. As a result the specific number of surface species should be much higher than in macroscopically crystalline materials. In addition, the estimated radii of the nanoaggregates also exceed the probing depth of XPS so that detection of surface atoms should be additionally enhanced. We therefore expect a significant proportion of the Al $2 p$ signal to come from the surface species in $\mathrm{HS} \mathrm{AlF}_{3}$, so components in the $\mathrm{Al} 2 \mathrm{p}$ peaks can plausibly be interpreted by comparison with surface $\mathrm{Al} 2 \mathrm{p}$ core level shifts derived from the ab initio calculations.

The results of the calculations allow individual shifts to be assigned to particular surface species. More specifically, computed BEs (Table 2) for surface $\mathrm{Al}$ ions bound to one or more dangling $\mathrm{F}$ or $\mathrm{OH}$ ions are generally at BEs that are between $0.4 \mathrm{eV}$ and $1.4 \mathrm{eV}$ lower than the $\mathrm{BE}$ of bulk $\mathrm{Al}$ ions. We therefore assign the peak fitted at a $\mathrm{BE}$ of $76.1 \mathrm{eV}$ to these species. Turning to the higher-BE component at $77 \mathrm{eV}$, the calculations indicate that there are two different types of surface $\mathrm{Al}$ ions that have $\mathrm{BEs}$ at higher energies than $\mathrm{Al}$ in bulk $\mathrm{AlF}_{3}$; these are some of the five-fold $\mathrm{Al}$ ions bound to five bridging $\mathrm{F}$ ions on the clean $\beta-\mathrm{AlF}_{3}$ (100) surface, and of a particular six-fold coordinated $\mathrm{Al}$ ion on the hydroxylated $\alpha-\mathrm{AlF}_{3}(0001)$ surface.

It is important to stress that the predicted low-BE-shifted Al $2 p$ components appear to be insensitive to the local coordination number. This is not a result one would perhaps expect. A lowered $\mathrm{BE}$ is often associated with a larger electron density at the emitting atom. ${ }^{40,41}$ Intuitively, one might assume that an under-coordinated $\mathrm{Al}$ ion would have a larger electron density than a fully-coordinated $\mathrm{Al}$ ion. However, in addition to the effects of local coordination, the rearrangement of the atoms at a surface results in a redistribution of the electron density. This effect is particularly significant here as $\mathrm{AlF}_{3}$ is highly ionic. For instance, the bond length of dangling $\mathrm{F}$ ions to $\mathrm{Al}$ ions is significantly shorter than the bulk $\mathrm{Al}-\mathrm{F}$ bond length, consequently the $\mathrm{Al}$ can see more of the electron density of the $\mathrm{F}$ ion than it would in the bulk. Undercoordinated $\mathrm{Al}$ ions bound to no dangling $\mathrm{F}$ ions have either no shift or a small shift to higher binding energies; the distortion of this site results in $\mathrm{Al}-\mathrm{F}$ bonds in the surface being significantly shorter than in the bulk. This effectively compensates for the lack of full coordination and, in general, results in a negligible shift in the $\mathrm{Al} 2 \mathrm{p}$ BE. In the case of the under-coordinated $\mathrm{Al}$ ions on row $\mathrm{B}$ of the $\beta-\mathrm{AlF}_{3}$ (100) surface this mechanism even appears to overcompensate, resulting in a slightly higher BE than in bulk Al ions. A shift to higher $\mathrm{BE}$ can also result from hydroxylation of neighbouring $\mathrm{Al}$ sites, as seen for the hydroxylated $\alpha-\mathrm{AlF}_{3}(0001)$ surface. This is also due to a distortion of the Al-F octahedra.

In summary, the calculated $\mathrm{Al} 2 \mathrm{p}$ BE values indicate that both fully-coordinated and under-coordinated $\mathrm{Al}^{3+}$ sites can, depending on the local geometry of the site, contribute to both the high BE peak at $77.0 \mathrm{eV}$ and the low $\mathrm{BE}$ peak at $76.1 \mathrm{eV}$. Consequently, the area of either peak is not expected to quantitatively correlate with surface area or Lewis acidity. The presence of dangling $\mathrm{F} / \mathrm{OH}$-groups, however, should correlate strongly with the appearance of the low BE peak. 
Table 2 Calculated initial state BE shifts relative to atoms in the centre of the $\mathrm{AlF}_{3}$ slabs. The coordination number $(\mathrm{CN})$ of the $\mathrm{Al}$ species is given in brackets; if the surface is hydroxylated the number of $\mathrm{OH}$ ions $\left(N_{\mathrm{OH}}\right)$ to which the $\mathrm{Al}$ ion is bound to is also given

\begin{tabular}{|c|c|c|}
\hline Surface & $\begin{array}{l}\mathrm{Al} 2 \mathrm{p} \mathrm{BE} \mathrm{shift} / \mathrm{eV} / \\
\text { species }(\mathrm{CN})\end{array}$ & F 1s BE shift/eV/species \\
\hline $\begin{array}{l}\alpha-\mathrm{AlF}_{3}(01 \overline{1} 2) \\
\text { clean surface }\end{array}$ & $-1.1 / \operatorname{Al}(5)$ & $\begin{array}{l}-0.6 \text { / Bridging } \mathrm{F} \text { between } \\
\mathrm{Al}(5) \mathrm{s} \\
-3.3 \text { Dangling } \mathrm{F} \text { to } \mathrm{Al}(5)\end{array}$ \\
\hline $\begin{array}{l}\alpha-\mathrm{AlF}_{3}(01 \overline{1} 2) \\
\text { hydroxylated } \\
\text { surface }\end{array}$ & $-1.4 / \operatorname{Al}(5)\left(N_{\mathrm{OH}}=5\right)$ & None \\
\hline$\alpha-\mathrm{AlF}_{3}(0001)$ & $-0.4 / \operatorname{Al}(4)$ & $+0.7 /$ Bridging $\mathrm{F}$ to $\mathrm{Al}(4)$ \\
\hline clean surface & $-1.2 / \operatorname{Al}(5)$ & $\begin{array}{l}+0.6 / \text { Bridging } \mathrm{F} \text { to } \mathrm{Al}(4) \\
-1.3 / \text { Distorted bridging } \\
\mathrm{F} \text { to } \mathrm{Al}(5) \\
\text {-2.3/Dangling } \mathrm{F} \text { to } \mathrm{Al}(4) \\
-3.0 / \text { Dangling } \mathrm{F} \text { to } \mathrm{Al}(5) \\
-3.3 / \text { Dangling } \mathrm{F} \text { to } \mathrm{Al}(5)\end{array}$ \\
\hline $\begin{array}{l}\alpha-\mathrm{AlF}_{3}(0001) \\
\text { hydroxylated }\end{array}$ & $\begin{array}{l}+0.4 / \mathrm{Al}(6) \text { close to } \\
\text { surface }\left(N_{\mathrm{OH}}=0\right)\end{array}$ & $+0.9 /$ Bridging $\mathrm{F}$ to $\mathrm{Al}(4)$ \\
\hline & $\begin{array}{l}-0.5 / \mathrm{Al}(5)\left(N_{\mathrm{OH}}=2\right) \\
-0.5 / \mathrm{Al}(6) \text { with dangling } \\
\mathrm{F}\left(N_{\mathrm{OH}}=0\right)\end{array}$ & $\begin{array}{l}+0.8 \text { /Bridging } \mathrm{F} \text { to } \mathrm{Al}(4) \\
+0.6 / \text { Bridging } \mathrm{F} \text { to } \mathrm{Al}(5)\end{array}$ \\
\hline \multirow[t]{2}{*}{$\begin{array}{l}\beta-\mathrm{AlF}_{3}(100) \\
\text { clean surface }\end{array}$} & $\begin{array}{l}-0.7 / \mathrm{Al}(4)\left(N_{\mathrm{OH}}=2\right) \\
+0.4 / \mathrm{Al}(5) \text { on row } \mathrm{B}\end{array}$ & $\begin{array}{l}-2.4 / \text { Dangling } \mathrm{F} \text { to } \mathrm{Al}(6) \\
+0.6 / \mathrm{F} \text { below } \mathrm{Al}(5) \text { on } \\
\text { row } \mathrm{B}\end{array}$ \\
\hline & $\begin{array}{l}-0.7 / \mathrm{Al}(6) \text { on row } \mathrm{A} \\
-0.8 / \mathrm{Al}(6) \text { on row } \mathrm{B}\end{array}$ & $\begin{array}{l}-0.5 / \text { Distorted bridging } \mathrm{F} \\
-0.7 / \text { Distorted bridging } \mathrm{F} \\
-3.2 / \text { Dangling } \mathrm{F} \text { to } \mathrm{Al}(6) \\
\text { on row } \mathrm{A} \\
-3.4 / \text { Dangling } \mathrm{F} \text { to } \mathrm{Al}(6) \\
\text { on row } \mathrm{B}\end{array}$ \\
\hline $\begin{array}{l}\beta-\mathrm{AlF}_{3}(100) \\
\text { hydroxylated } \\
\text { surface }\end{array}$ & $\begin{array}{l}-0.8 / \mathrm{Al}(6) \text { row } \mathrm{A} \\
\left(N_{\mathrm{OH}}=1\right) \\
-1.0 / \mathrm{Al}(6) \text { row } \mathrm{B} \\
\left(N_{\mathrm{OH}}=1\right)\end{array}$ & $\begin{array}{l}+0.7 / \mathrm{F} \text { below } \mathrm{Al}(5) \text { on } \\
\text { row } \mathrm{B} \\
-0.7 / \text { Distorted bridging } \mathrm{F}\end{array}$ \\
\hline
\end{tabular}

\section{F 1s}

The F 1s BEs (Fig. 3, Table 1) of $\mathrm{HS} \mathrm{AlF}_{3}$ are, to within a few $0.1 \mathrm{eV}$, centred at the $\mathrm{BE}$ of the $\mathrm{F} 1 \mathrm{~s}$ level in $\alpha-\mathrm{AlF}_{3}$. However, the peaks for the $\mathrm{HS} \mathrm{AlF}_{3}$ materials are significantly broadened and most of them require fitting with at least one additional component at slightly higher BE to reproduce the peak shapes (Table 1). The FWHMs of these additional peaks are similarly broad as those of the main $F$ 1s peaks in the data, indicating a distribution of various species. The only exception is the secondary peak fitted for HS $116 \mathrm{~m}^{2} \mathrm{~g}^{-1}$, where the secondary peak is almost as narrow as in the $\alpha-\mathrm{AlF}_{3}$ reference, which might indicate that a certain amount of stoichiometric $\mathrm{AlF}_{3}$ phase had nucleated during the preparation of this material.

The ab initio calculations predict that dangling $\mathrm{F}$ ions, whether bound to six- or five-fold coordinated Al ions, are shifted to lower BEs by around $3 \mathrm{eV}$, while dangling $\mathrm{F}$ ions bound to four-fold $\mathrm{Al}$ ions are shifted to lower $\mathrm{BEs}$ by around $2.3 \mathrm{eV}$ (Table 2). There is no evidence for any such strongly low-BE-shifted components in any of the $\mathrm{HS} \mathrm{AlF}_{3}$ data (Fig. 3), indicating that significant amounts of dangling $F$ ions are absent. The broadened nature of the F 1s peaks suggests, however, that there is a distribution of $\mathrm{F}$ ions with slightly varying $\mathrm{BEs}$ in the $\mathrm{HS} \mathrm{AlF}_{3}$ materials. Leaving aside the calculated data for the $\alpha-\mathrm{AlF}_{3}$ (0001) surfaces, which are probably the least representative surfaces, we can correlate

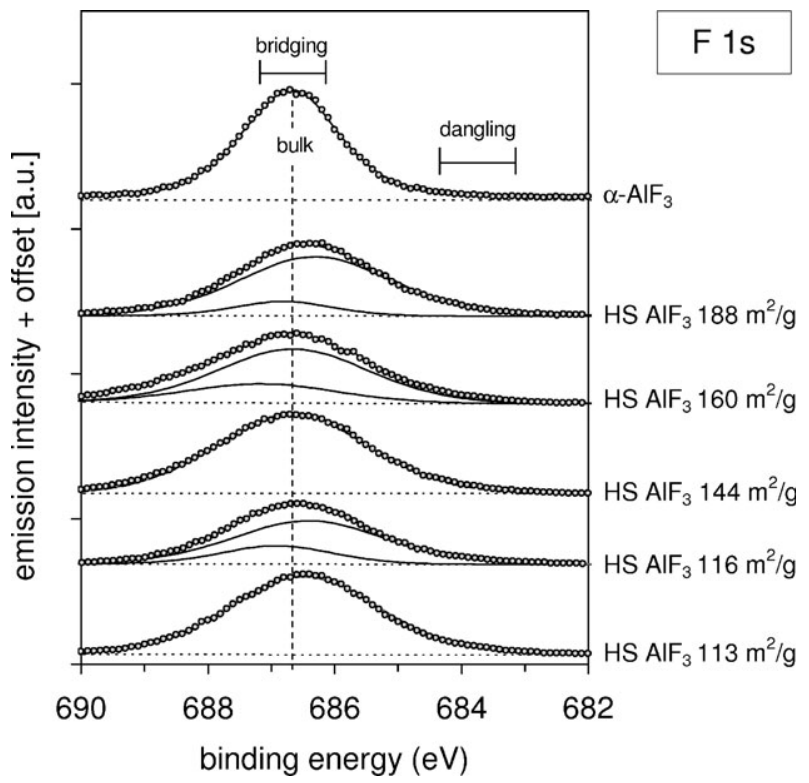

Fig. $3 \mathrm{~F}$ 1s XPS photoemission data for $\alpha-\mathrm{AlF}_{3}$ and the $\mathrm{HS} \mathrm{AlF}_{3}$ samples. The intensity of the spectra was scaled to result in similar peak heights.

shifts to slightly lower and higher BEs with two types of species. The higher $\mathrm{BE}$ components, which are visible as a second fitted peak in several of the $\mathrm{HS} \mathrm{AlF}_{3}$ spectra (Fig. 3), can be identified with $\mathrm{F}$ ions in the second layer, below the under-coordinated $\mathrm{Al}^{3+}$ ions. In addition, we also predict similar shifts to lower $\mathrm{BE}$ for $\mathrm{F}$ ions in distorted bridging positions in the surface plane. However, the experimental data are not of sufficient resolution to resolve all these features, and we expect them to simply contribute to the FWHM of the observed peaks.

\section{O 1s}

The O 1s data (Fig. 4, Table 1), which have received relatively little attention in previous XPS studies of fluorides, are expected to be complex because they can arise from (i) $\mathrm{O}$-species intrinsic to the preparation of the $\mathrm{AlF}_{3}$ materials, (ii) the adsorption and/or dissociation of water during handling of the materials in the glovebox or laboratory ambient, and/or (iii) from extrinsic surface contamination, most notably oxygenated hydrocarbons from the laboratory ambient, including contamination associated with the biological environment such as complex carbohydrates or lipids. Less likely, but not entirely impossible, is adsorption from the residual gas of the vacuum in the XPS instrument.

Quantitative analysis of elemental concentrations within the surface region probed by XPS revealed that oxygen concentrations were on the order of only $10-15 \%$ of the fluorine concentrations. This indicates that uptake of $\mathrm{O}$ species from the ambient by $\mathrm{HS} \mathrm{AlF}_{3}$ is not much faster than on materials considered to be chemically more inert. For example, the $\alpha-\mathrm{AlF}_{3}$ reference sample, which was a crystal facet obtained by cleaving of a larger $\alpha-\mathrm{AlF}_{3}$ crystal in air immediately prior to loading into the XPS apparatus, exhibited an $\mathrm{O}: \mathrm{F}$ ratio of approximately $1: 11$. This result confirms a previous conclusion drawn from in situ IR studies ${ }^{14}$ 


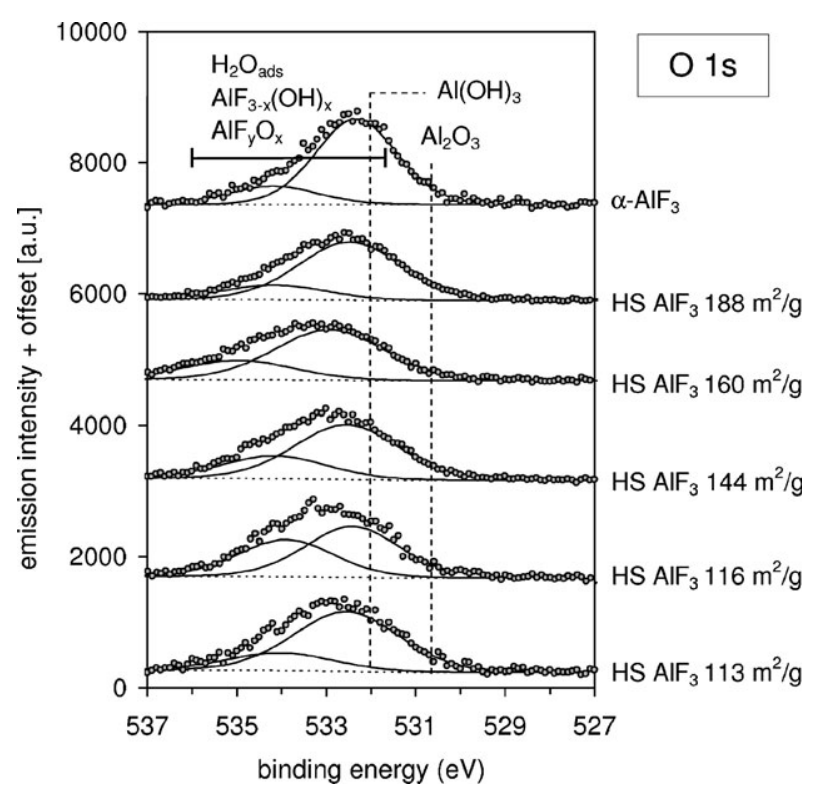

Fig. $4 \mathrm{O}$ 1s photoemission data for $\alpha-\mathrm{AlF}_{3}$ and several $\mathrm{HS} \mathrm{AlF}_{3}$ samples. The dashed vertical bars indicate previously reported BEs of $\mathrm{Al}_{2} \mathrm{O}_{3},{ }^{42} \mathrm{Al}(\mathrm{OH})_{3},{ }^{42}$ as well as expected ranges for hydroxyfluoridic ${ }^{43}$ and oxyfluoridic ${ }^{15}$ phases, as well as for adsorbed water on fluoride surfaces (Table 3). In comparison with the F 1s data the signal-tonoise quality of these data is comparatively poor because $\mathrm{O}$ concentrations were only $10-15 \%$ of the $\mathrm{F}$ concentrations.

that $\mathrm{HS} \mathrm{AlF}_{3}$ is much less sensitive to hydrolysis in air than other highly Lewis-acidic Al compounds, most notably aluminium chlorofluoride (ACF).

For $\mathrm{HS} \mathrm{AlF}_{3}$ samples that were handled in essentially the same way as in the present study the mentioned in situ IR investigations revealed broad $\nu(\mathrm{OH})$ bands that are characteristic for the presence of hydroxyl groups and/or adsorbed $\mathrm{H}_{2} \mathrm{O}$ in non-crystalline environments. ${ }^{14} \mathrm{~A}$ certain level of hydroxylation and adsorbed water species thus appear to be characteristic even for freshly prepared $\mathrm{HS} \mathrm{AlF}_{3}$ materials. Re-fluorination in the IR cell did not remove these species. ${ }^{14}$ The in situ IR spectra of untreated, briefly air-exposed HS $\mathrm{AlF}_{3}$ also exhibited comparatively sharp but weak $\nu(\mathrm{OH})$ and $\delta(\mathrm{OH})$ bands. This indicates the presence of structural $\mathrm{OH}$ groups, probably due to residual $\mathrm{AlF}_{3-x}(\mathrm{OH})_{x}$ units in the sample, and possibly also associated with the appearance of oxyfluoride $\left(\mathrm{AlO}_{x} \mathrm{~F}_{y}\right)$ islands by exposure to $\mathrm{H}_{2} \mathrm{O}$ during handling in air. ${ }^{14}$ The concentration of these structural $\mathrm{O}$ species could be reduced by re-fluorination in a $\mathrm{CHF}_{3}$ stream. ${ }^{14}$ Structural $\mathrm{OH}$ and $\mathrm{O}$ species are therefore probably absent immediately after $\mathrm{HS} \mathrm{AlF}_{3}$ has been prepared by fluorination with a $\mathrm{CFC}$ or HFC at temperatures of $500-600 \mathrm{~K}^{14}$

However, as highlighted by recent computationally derived phase diagrams for $\alpha-\mathrm{AlF}_{3}$ surfaces, ${ }^{37}$ it is predicted that the uptake of adsorbed water and formation of hydroxylated surfaces are thermodynamically favoured under all practically accessible humidity conditions at atmospheric pressure and room temperature. Excluding any $\mathrm{OH}$ or $\mathrm{H}_{2} \mathrm{O}$ contamination in $\mathrm{HS} \mathrm{AlF}_{3}$ handled at room temperature would require exceptional experimental and technical effort, which was not available for this and the previous IR study. Relative elementary calculations of surface collision rates ${ }^{44}$ show that exposure to approximately $10^{-6} \mathrm{mbar}$ of $\mathrm{H}_{2} \mathrm{O}$ vapour for a few seconds is sufficient to form a monomolecular $\mathrm{H}_{2} \mathrm{O}$ overlayer, assuming that all surface collisions of gas phase $\mathrm{H}_{2} \mathrm{O}$ molecules lead to their adsorption. Given the strong reactivity of $\mathrm{HS} \mathrm{AlF}_{3}$ a contamination surface layer of adsorbed water can therefore only be excluded if every step of the investigations (synthesis, sample handling and spectroscopic analysis) was to be performed at humidity levels at least in the ppb range. The required humidity levels are orders of magnitude below those achievable in gloveboxes, which typically operate with residual $\mathrm{H}_{2} \mathrm{O}$ pressures in the ppm region. Even the handling of freshly fluorinated product under a protecting Ar atmosphere and in a glovebox exposes the samples to higher humidity levels, so that Lewis sites are probably readily covered with $\mathrm{OH}$ or $\mathrm{H}_{2} \mathrm{O}$ surface species.

We experimented briefly with transferring some $\mathrm{HS} \mathrm{AlF}_{3}$ products into the XPS analysis chamber, by opening the glass ampoules with the samples in a purpose-built glovebox (humidity level below $10 \mathrm{ppm}$ ) that connected directly to the loading bay of the XPS apparatus. We found no fundamental difference to the $\mathrm{O} 1 \mathrm{~s}$ results obtained without the use of the glovebox, suggesting that most of the $\mathrm{O}$ content determined by XPS was already present prior to exposure to air, in line with the results of previous IR investigations. We cannot exclude that some additional multilayer adsorption of $\mathrm{H}_{2} \mathrm{O}$ might take place on the samples, but one should keep in mind that weakly bound surface species, especially adsorbed multilayers of $\mathrm{H}_{2} \mathrm{O}$, will tend to have been removed from the samples under the ultra-high vacuum conditions of the XPS system.

We observed multiple O 1s BEs (Fig. 4), which can again be grouped into two principal components, one centred at $532.3-532.8 \mathrm{eV}$ and one at $533.8-534.7 \mathrm{eV}$. The BE ranges of these two groups of $\mathrm{O}$ species are very similar to those observed in a recent study of sol-gel prepared $\mathrm{HS} \mathrm{MgF}_{2}$, where the lower-BE components were assigned to adsorbed water and the higher-BE species to hydroxyfluoride species, ${ }^{43}$ which are likely to be formed with residual water contamination during preparation or after preparation by exposure of the HS fluoride to water contained in the ambient air.

Generally, it is known that adsorbed water on $\mathrm{Al}$ hydroxides tends to exhibit an approximately $1 \mathrm{eV}$ higher $\mathrm{O} 1 \mathrm{~s} \mathrm{BE}$ than $\mathrm{OH}$ groups in hydroxides, which in turn appear at approximately $1.5 \mathrm{eV}$ higher $\mathrm{O} 1 \mathrm{~s} \mathrm{BE}$ than the corresponding oxides. Relevant $\mathrm{BE}$ values of aluminium oxides, aluminium hydroxides and adsorbed water on these materials have recently been measured with the same instrument model as used in the present study ${ }^{42}$ and have been indicated in Fig. 4. It can be seen that all experimental $\mathrm{O} 1 \mathrm{~s}$ BEs reported here are too high to be due to oxidic $\mathrm{Al}_{2} \mathrm{O}_{3}$-like species and we can conclude that all observed $\mathrm{O}$ 1s signals must relate to either hydroxidic species, adsorbed $\mathrm{H}_{2} \mathrm{O}$ (including strongly polarised $\mathrm{H}_{2} \mathrm{O}$ species adsorbed on Lewis sites), hydroxyfluoridic ${ }^{43}$ or oxyfluoridic ${ }^{15}$ species, i.e., electron-deficient $\mathrm{OH}$ or $\mathrm{O}$ species bound to $\mathrm{AlF}_{x}$ centres. The broad $\mathrm{O}$ 1s emission lines therefore suggest that exposure of the $\mathrm{HS} \mathrm{AlF}_{3}$ materials to ambient $\mathrm{H}_{2} \mathrm{O}$ results in significant $\mathrm{H}_{2} \mathrm{O}$ adsorption and hydroxylation, even to the point of some hydration and 


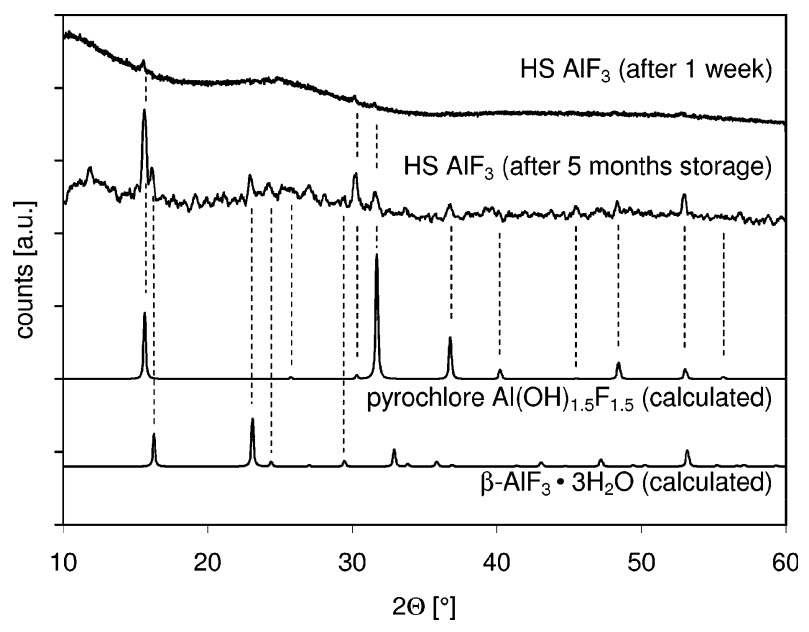

Fig. 5 X-Ray diffraction patterns of $\mathrm{HS} \mathrm{AlF}_{3} 309 \mathrm{~m}^{2} \mathrm{~g}^{-1}$ after storage for a day (top pattern) and for 5 months (second pattern from top) in a standard screw-cap sample vial in the laboratory. For comparison, calculated XRD patterns of the pyrochlore phase $\mathrm{Al}(\mathrm{OH})_{1.5} \mathrm{~F}_{1.5}{ }^{45}$ and of $\beta-\mathrm{AlF}_{3} \cdot 3 \mathrm{H}_{2} \mathrm{O}^{23}$ are shown. It can be seen that concomitant formation of the hydroxyfluoride phase and the hydrate has begun to take place. Weak lines, evidence for the presence of small amounts of pyrochlore phase, are even visible in the pattern taken after 1 week of storage. Calculated patterns were obtained with PowderCell. ${ }^{46}$

hydrolysis to hydroxyfluoridic or oxyfluoridic species. In line with the formation of hydroxyfluoridic species, X-ray diffraction analysis (Fig. 5) of a $\mathrm{HS} \mathrm{AlF}_{3} 309 \mathrm{~m}^{2} \mathrm{~g}^{-1}$ sample stored in a standard sample vial for 5 months reveals that the crystallisation of a hydroxyfluoride phase with pyrochlore structure of stoichiometry $\mathrm{Al}(\mathrm{OH})_{1.5} \mathrm{~F}_{1.5}{ }^{45}$ has begun to take place. Additional lines in the diffraction pattern can be assigned to the formation of the hydrate phase $\beta-\mathrm{AlF}_{3} \cdot 3 \mathrm{H}_{2} \mathrm{O}{ }^{23}$ It should be noted that the XRD patterns do not provide any evidence for the presence of stoichiometric $\mathrm{Al}(\mathrm{OH})_{3}$ or $\mathrm{Al}_{2} \mathrm{O}_{3}$ phases.

Formation of dangling $\mathrm{OH}$ species by hydrolysis of dangling $\mathrm{F}$ sites would require the formation of adsorbed HF, which is not evident from the XPS data. To understand the lack of evidence for HF we need to remember that the concentration of $\mathrm{O}$ species within the depth region probed by XPS is only about $10-15 \%$ of the $\mathrm{F}$ content. The oxygen content in the bulk of the samples, i.e., below the surface region accessible by XPS is likely to be even lower. Additionally, not all of the observed $\mathrm{OH}$ species will be dangling species. As a result we might not detect any XPS signal of HF formed by hydrolysis because of its low concentration relative to the remaining bulk $\mathrm{F}$ content. Moreover, the beginning crystallisation of $\beta-\mathrm{AlF}_{3}$ trihydrate after long exposure to low level humidity suggests that uptake of $\mathrm{H}_{2} \mathrm{O}$ as hydrate might be a significant process. It appears even possible that a hydration process could cause phase separation of any initially present hydroxidic contamination into the observed hydroxyfluoride phase. The hydroxyfluoride would then remain a minor component of the overall sample, which would in fact explain the relatively weak lines observed in the experimental XRD pattern. If the main process occurring during exposure to $\mathrm{H}_{2} \mathrm{O}$ was hydration then no formation of significant concentrations of HF would be expected.

Both the formation of hydrate and hydroxyfluoride are compatible with the presence of the $\mathrm{O} 1 \mathrm{~s}$ emission tail towards higher BEs, as evident from the $\mathrm{O}$ 1s BEs calculated for the hydroxylated $\alpha$ - and $\beta-\mathrm{AlF}_{3}$ surfaces, as well as those for adsorbed $\mathrm{H}_{2} \mathrm{O}$ (Fig. 6, Table 3). The correlation between experimental and calculated data is somewhat less clear than in the case of the $\mathrm{F} 1 \mathrm{~s}$ and $\mathrm{Al} 2 \mathrm{p}$ emissions, because we cannot rely on a bulk oxygen species as an internal energy reference, and hence we can only offer an interpretation based on BE shifts between various surface species (Fig. 6, Table 3). Most importantly, however, it can be seen that hydroxyfluoridic surface $\mathrm{OH}$ species appear to cover the same $\mathrm{BE}$ range as water adsorbed on $\mathrm{AlF}_{3}$ surfaces. The calculations also predict that the BE shifts for these species span a wide range, because they are environment-dependent and the presence or absence of $\mathrm{H}$ bonding is critical in determining the absolute value of the BE. This explains the large FWHM of the high-BE tail in the experimental $\mathrm{O}$ 1s data, as well as the strong variations in the BE position of the peak used to model this tail.

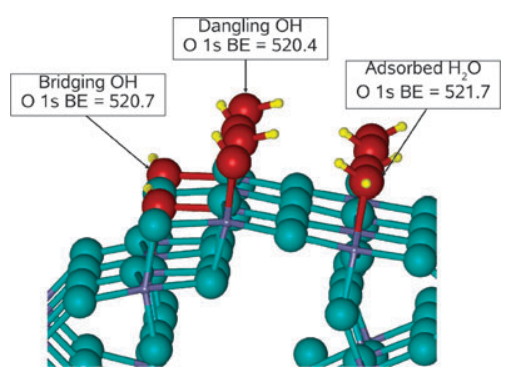

Fig. 6 The theoretical $\mathrm{O}$ 1s binding energies (in $\mathrm{eV}$ ) for the hydroxylated and hydrated $\beta-\mathrm{AlF}_{3}(100)$ surface.

Table 3 Calculated O 1s BEs in for various hydroxylated surfaces. The Greek letter $\Delta$ indicates the shift relative to the highest BE

\begin{tabular}{|c|c|c|}
\hline Sample & $\mathrm{O} 1 \mathrm{~s} \mathrm{BE} / \mathrm{eV}$ & Species \\
\hline \multirow{4}{*}{$\begin{array}{l}\alpha-\mathrm{AlF}_{3}(01 \overline{1} 2) \\
\text { hydroxylated } \\
\text { surface }\end{array}$} & 522.1 & $\begin{array}{l}\text { Bridging } \mathrm{OH} \text { to } \mathrm{Al}(6) \\
\text { and } \mathrm{Al}(5)\end{array}$ \\
\hline & $521.5(\Delta=-0.6)$ & $\begin{array}{l}\text { Bridging } \mathrm{OH} \text { to } \mathrm{Al}(6) \\
\text { and } \mathrm{Al}(5)\end{array}$ \\
\hline & $521.2(\Delta=-0.9)$ & $\begin{array}{l}\text { Bridging } \mathrm{OH} \text { to } \mathrm{Al}(5) \\
\text { and } \mathrm{Al}(5)\end{array}$ \\
\hline & $520.0(\Delta=-2.1)$ & Dangling $\mathrm{OH}$ to $\mathrm{Al}(5)$ \\
\hline \multirow{5}{*}{$\begin{array}{l}\alpha-\mathrm{AlF}_{3}(0001) \\
\text { hydroxylated } \\
\text { surface } \\
\beta-\mathrm{AlF}_{3}(100) \\
\text { hydroxylated } \\
\text { surface }\end{array}$} & 521.9 & Distorted bridging $\mathrm{OH}$ \\
\hline & $521.1(\Delta=-0.8)$ & Dangling $\mathrm{OH}$ to $\mathrm{Al}(4)$ \\
\hline & $520.5(\Delta=-1.4)$ & Dangling $\mathrm{OH}$ to $\mathrm{Al}(5)$ \\
\hline & 520.2 & $\begin{array}{l}\text { Dangling } \mathrm{OH} \text { to } \mathrm{Al}(6) \text {, } \\
\text { row } \mathrm{B}\end{array}$ \\
\hline & $519.9(\Delta=-0.3)$ & $\begin{array}{l}\text { Dangling } \mathrm{OH} \text { to } \mathrm{Al}(6) \text {, } \\
\text { row A }\end{array}$ \\
\hline \multirow{5}{*}{$\begin{array}{l}\beta-\mathrm{AlF}_{3}(100) \\
\text { hydroxylated } \\
\text { surface and } \\
\text { adsorbed } \mathrm{H}_{2} \mathrm{O}\end{array}$} & 522.1 & $\begin{array}{l}\mathrm{H}_{2} \mathrm{O} \text { adsorbed to } \mathrm{Al}(5), \\
\text { row A }\end{array}$ \\
\hline & $521.7(\Delta=-0.4)$ & $\begin{array}{l}\mathrm{H}_{2} \mathrm{O} \text { adsorbed to } \mathrm{Al}(5), \\
\text { row } \mathrm{A}\end{array}$ \\
\hline & $520.7(\Delta=-1.4)$ & Bridging $\mathrm{OH}$ \\
\hline & $520.4(\Delta=-1.7)$ & $\begin{array}{l}\text { Dangling } \mathrm{OH} \text { to } \mathrm{Al}(6) \text {, } \\
\text { row A }\end{array}$ \\
\hline & $520.2(\Delta=-1.9)$ & $\begin{array}{l}\text { Dangling } \mathrm{OH} \text { to } \mathrm{Al}(6) \text {, } \\
\text { row } \mathrm{B}\end{array}$ \\
\hline
\end{tabular}




\section{Conclusions}

The combination of experimental and theoretical core level BE investigations demonstrates that the assignment of surface features to different BE components in XPS data is not straightforward; it is important to take local structure and stoichiometry into account and not just coordination. Ab initio calculations have shown that an $\mathrm{Al} 2 \mathrm{p}$ emission component at a $\mathrm{BE}$ lower than in the $\alpha-\mathrm{AlF}_{3}$ bulk is predicted to occur for $\mathrm{Al}$ ions bound to one or more dangling $\mathrm{F}$ or $\mathrm{OH}$ groups. The lack of evidence for dangling $\mathrm{F}$ surface groups, in conjunction with the significant signal of adsorbed $\mathrm{H}_{2} \mathrm{O}$ or $\mathrm{OH}$ groups, indicates either that freshly prepared $\mathrm{HS} \mathrm{AlF}_{3}$ might not contain a significant concentration of dangling $\mathrm{F}$ ions, or that any dangling $\mathrm{F}$ ions originally present are quickly substituted for $\mathrm{OH}$ groups under the conditions of handling the materials at room temperature in the laboratory. Ab initio calculations have shown that bridging $\mathrm{OH}$ groups are thermodynamically more stable than dangling $\mathrm{OH}$ groups, ${ }^{37}$ but it appears that any dangling species in $\mathrm{HS} \mathrm{AlF}_{3}$ are of hydroxylic nature. Bridging $\mathrm{F}$ ions at the surface may nevertheless be replaced by $\mathrm{OH}$ groups and water may adsorb over under-coordinated $\mathrm{Al}$ ions. The absence of evidence for dangling $\mathrm{F}$ groups in the HS $\mathrm{AlF}_{3}$ materials may also suggest that freshly prepared $\mathrm{HS} \mathrm{AlF}_{3}$ materials contain a high concentration of under-coordinated Al sites with very high Lewis acidity, confirming previous FTIR evidence obtained with adsorbed CO. ${ }^{14}$ Any Brønsted acid species formed must be removed, for example by re-fluorination at elevated temperature, ${ }^{14}$ before $\mathrm{HS} \mathrm{AlF}_{3}$ reagents can fully develop their Lewis acidity under reaction conditions. A limited supply of $\mathrm{H}_{2} \mathrm{O}$ during storage appears to allow the crystallisation of hydroxyfluoride and hydrated fluoride phases.

A general conclusion of the current work on $\mathrm{AlF}_{3}$ materials is that properties such as Lewis acidity and catalytic activity depend sensitively on local geometric structure and not just on local coordination. For example, five-fold coordination of an Al ion is not a sufficient condition for a strong Lewis acid centre. The most reactive sites identified in previous calculations are $\mathrm{Al}$ ions coordinated to five bridging $\mathrm{F}$ ions, while five-fold and four-fold $\mathrm{Al}$ ions, bound to one or more dangling $\mathrm{F}$ ions, are less reactive. ${ }^{11,24,25}$ The challenge for preparative chemistry is therefore to create the right kind of under-coordinated sites, with suitable local geometry permitting the creation of accessible and strong Lewis centres.

\section{Acknowledgements}

This project was funded through the European Union 6th Framework Programme (FP6, FUNFLUOS, Contract No. NMP3-CT-2004-5005575). AM held a Marie-Curie Fellowship awarded through the EU FP6-funded EXPERT programme at The University of Manchester. The calculations were performed in part on the STFC's SCARF system, in part on the NW-Grid system located at the STFC's Daresbury Laboratory, in part on resources provided by the High Performance Computing Service at Imperial College and in part on the HPCx system where computer resources were provided via our membership of the UK's HPC Materials
Chemistry Consortium and funded by EPSRC (portfolio grant EP/D504872). We also thank all participants of the FUNFLUOS network for valuable discussions.

\section{References}

1 I. Kiricsi and J. B. Nagy, Appl. Catal. A: General, 2004, 271, 27.

2 E. Kemnitz and D. H. Menz, Prog. Solid State Chem., 1998, 26, 97.

3 C. G. Krespan and V. A. Petrov, Chem. Rev., 1996, 96, 3269.

4 Y. V. Kissin, Catal. Rev. Sci. Eng., 2001, 43, 85.

5 K. O. Christe, D. A. Dixon, D. McLemore, W. W. Wilson, J. A. Sheehy and J. A. Boatz, J. Fluorine Chem., 2000, 101, 151.

6 P. Daniel, A. Bulou, M. Rousseau, J. Nouet, J. L. Fourquet, M. Leblanc and R. Burriel, J. Phys. Condens. Matter., 1990, 2, 5663.

7 S. L. M. Schroeder and N. Weiher, Phys. Chem. Chem. Phys., 2006, 8, 1807.

8 A. Wander, B. G. Searle, C. L. Bailey and N. M. Harrison, J. Phys. Chem. B, 2005, 109, 22935.

9 A. Wander, C. L. Bailey, S. Mukhopadhyay, B. G. Searle and N. M. Harrison, J. Phys. Chem. C, 2008, 112, 6515.

10 A. Wander, C. L. Bailey, S. Mukhopadhyay, B. G. Searle and N. M. Harrison, J. Mater. Chem., 2006, 16, 1906.

11 A. Wander, C. L. Bailey, B. G. Searle, S. Mukhopadhyay and N. M. Harrison, Phys. Chem. Chem. Phys., 2005, 7, 3989.

12 S. K. Ruediger, U. Gross, M. Feist, H. A. Prescott, S. C. Shekar, S. I. Troyanov and E. Kemnitz, J. Mater. Chem., 2005, 15, 588.

13 E. Kemnitz, U. Gross, S. Rüdiger and C. S. Shekar, Angew. Chem., Int. Ed., 2003, 42, 4251.

14 T. Krahl, A. Vimont, G. Eltanany, M. Daturi and E. Kemnitz, J. Phys. Chem. C, 2007, 111, 18317.

15 O. Boese, E. Kemnitz, W. E. S. Unger and S. L. M. Schroeder, Phys. Chem. Chem. Phys., 2002, 4, 2824.

16 O. Böse, E. Kemnitz, A. Lippitz and W. E. S. Unger, Appl. Surf. Sci., 1997, 120, 181.

17 O. Böse, E. Kemnitz, A. Lippitz and W. E. S. Unger, Fres. J. Anal. Chem., 1997, 358, 175.

18 A. Hess, E. Kemnitz, A. Lippitz, W. E. S. Unger and D. H. Menz, J. Catal., 1994, 148, 270.

19 U. Gross, S. Rudiger, E. Kemnitz, K. W. Brzezinka, S. Mukhopadhyay, C. Bailey, A. Wander and N. Harrison, J. Phys. Chem. A, 2007, 111, 5813.

20 P. J. Chupas and C. P. Grey, J. Catal., 2004, 224, 69.

21 P. J. Chupas, M. F. Ciraolo, J. C. Hanson and C. P. Grey, J. Am. Chem. Soc., 2001, 123, 1694.

22 R. Konig, G. Scholz, N. H. Thong and E. Kemnitz, Chem. Mater., 2007, 19, 2229.

23 E. Kemnitz, U. Gross, S. Rudiger, G. Scholz, D. Heidemann, S. I. Troyanov, I. V. Morosov and M. H. Lemee-Cailleau, Solid State Sci., 2006, 8, 1443.

24 C. L. Bailey, A. Wander, B. G. Searle, S. Mukhopadhyay and N. M. Harrison, J. Chem. Phys., 2008, 128, 224703.

25 M. Daturi, D. Dambournet, C. L. Bailey, A. Vimont, S. Mukhopadhyay, A. Wander and N. M. Harrison, unpublished results.

26 N. Fairley and A. Carrick, The CASA Cookbook Recipes for XPS Data Processing, pt. 1, Acolyte Science, Knutsford, Cheshire, UK, 2005.

27 D. A. Shirley, Phys. Rev. B, 1972, 5, 4709.

28 J. S. Stevens and S. L. M. Schroeder, Surf. Interface Anal., 2009, 41, 453.

29 C. J. Powell, Appl. Surf. Sci., 1995, 89, 141.

30 M. P. Seah, I. S. Gilmore and S. J. Spencer, Surf. Interface Anal., 1998, 26, 617.

31 M. P. Seah, L. S. Gilmore and G. Beamson, Surf. Interface Anal., 1998, 26, 642.

32 R. Dovesi, V. R. Saunders, C. Roetti, R. Orlando, C. M. ZicovichWilson, F. Pascale, B. Civalleri, K. Doll, N. M. Harrison, I. J. Bush, P. D'Arco and M. Llunell, Crystal 2006 Users Manual, University of Torino, Torino, Italy, 2007.

33 C. Pisani, R. Dovesi and C. Roetti, Hartree-Fock Ab Initio Treatment of Crystalline Systems, Lecture Notes in Chemistry, Springer Verlag, Heidelberg, 1988, vol. 48. 
34 A. D. Becke, J. Chem. Phys., 1993, 98, 5648.

35 C. Lee, W. Yang and R. G. Parr, Phys. Rev. B, 1988, 37, 785.

36 J. Muscat, A. Wander and N. M. Harrison, Chem. Phys. Lett., 2001, 342, 397.

37 C. L. Bailey, S. Mukhopadhyay, A. Wander, B. G. Searle and N. M. Harrison, J. Phys. Chem. C, 2009, 113, 4976.

38 S. Mukhopadhyay, C. L. Bailey, A. Wander, B. G. Searle, C. A. Muryn, S. L. M. Schroeder, R. Lindsay, N. Weiher and N. M. Harrison, Surf. Sci., 2007, 601, 4433.

39 C. J. Powell and A. Jablonski, NIST Electron EffectiveAttenuation-Length Database, National Institute of Standards and Technology, Gaithersburg, MD, USA, 2001.

40 S. Hüfner, Photoelectron Spectroscopy. Principles and Applications, Springer Verlag, Berlin, Heidelberg, New York, 2nd edn, 1996.
41 Practical Surface Analysis. Vol. 1 - Auger and X-ray Photoelectron Spectroscopy, ed. D. Briggs, M. P. Seah, John Wiley \& Sons, Chichester, 2nd edn, 1990.

42 J. T. Kloprogge, L. V. Duong, B. J. Wood and R. L. Frost, J. Colloid Interface Sci., 2006, 296, 572.

43 S. Wuttke, S. M. Coman, G. Scholz, A. Vimont, M. Daturi, S. L. M. Schroeder and E. Kemnitz, Chem.-Eur. J., 2008, 14, 11488.

44 R. I. Masel, Principles of Adsorption and Reaction on Solid Surfaces, Wiley, New York, 1st edn, 1996.

45 J. L. Fourquet, M. Riviere, A. Le Bail, M. Nygrens and J. Grins, Eur. J. Solid State Inorg. Chem., 1988, 25, 535.

46 W. Kraus and G. Nolze, Powder Cell 2.4, Federal Institute for Materials Testing and Research (BAM), Berlin, Germany, 2000 